\title{
REVIEW \\ Iterative development and the scope for plasticity: contrasts among trait categories in an adaptive radiation
}

\begin{abstract}
SA Foster ${ }^{1}$, MA Wund ${ }^{2}$, MA Graham ${ }^{1}$, RL Earley $^{3}$, R Gardiner $^{2}$, T Kearns $^{2}$ and JA Baker ${ }^{1}$
Phenotypic plasticity can influence evolutionary change in a lineage, ranging from facilitation of population persistence in a novel environment to directing the patterns of evolutionary change. As the specific nature of plasticity can impact evolutionary consequences, it is essential to consider how plasticity is manifested if we are to understand the contribution of plasticity to phenotypic evolution. Most morphological traits are developmentally plastic, irreversible, and generally considered to be costly, at least when the resultant phenotype is mis-matched to the environment. At the other extreme, behavioral phenotypes are typically activational (modifiable on very short time scales), and not immediately costly as they are produced by constitutive neural networks. Although patterns of morphological and behavioral plasticity are often compared, patterns of plasticity of life history phenotypes are rarely considered. Here we review patterns of plasticity in these trait categories within and among populations, comprising the adaptive radiation of the threespine stickleback fish Gasterosteus aculeatus. We immediately found it necessary to consider the possibility of iterated development, the concept that behavioral and life history trajectories can be repeatedly reset on activational (usually behavior) or developmental (usually life history) time frames, offering fine tuning of the response to environmental context. Morphology in stickleback is primarily reset only in that developmental trajectories can be altered as environments change over the course of development. As anticipated, the boundaries between the trait categories are not clear and are likely to be linked by shared, underlying physiological and genetic systems.
\end{abstract}

Heredity (2015) 115, 335-348; doi:10.1038/hdy.2015.66; published online 5 August 2015

\section{INTRODUCTION}

Integration of the concept of phenotypic plasticity into our understanding of the evolutionary process has been slow in coming, and appreciation of the role of plasticity in evolution has shifted more than once over the last 100 years. Early proponents of the idea that plastic organismal responses to the environment could themselves evolve, and indeed could guide evolutionary change, were eloquent in their arguments (for example, Weismann, 1894; Morgan, 1896; Baldwin, 1902). Nevertheless, this viewpoint fell out of favor as some of the most remarkable evolutionary biologists of the last century attempted to reconcile classical and population genetics with evolutionary theory (Wcislo, 1989; Schlichting and Pigliucci, 1998; West-Eberhard, 2003). Only in the last 25 years has the importance of phenotypic plasticity as a contributor to evolutionary change re-emerged as a central focus of evolutionary theory (for example, West-Eberhard, 1989, 2003; DeWitt et al., 1998; Schlichting and Pigliucci, 1998), and we are only beginning to understand and appreciate its influence on the evolutionary process (for example, Hallgrímsson and Hall, 2011; Moczek et al., 2011, this issue; Pfennig et al., 2010; Snell-Rood et al., 2010; Paaby and Rockman, 2014).

Early publications often emphasized the influence of behavior, as its expression is typically highly plastic and modifiable over very short time frames. Thus, behavioral shifts were viewed as having the potential to 'rescue' populations experiencing marked environmental transitions, enabling them to persist until natural selection could enhance the genetic fit of the population to the novel environment ('Baldwin Effect' sensu Simpson, 1953). Although a role for behavior in evolution was discussed occasionally during the period of the Modern Synthesis (most prominently in Roe and Simpson, 1958), as interest in the role of plasticity re-emerged, the focus was primarily on morphology as the trait category of greatest theoretical import due apparently, to the perceived high costs associated with plastic morphological transitions (Bradshaw, 1965; Scheiner, 1993; Gotthard and Nylin, 1995; Schlichting and Pigliucci, 1998) (but see Bateson, 1988; Wcislo, 1989; West-Eberhard, 1989). During the same period, the field of behavioral ecology developed separately, an occurrence that may account for the failure to incorporate behavior into theory concerning the role of plasticity in evolution, and also for the rarity with which those studying behavior incorporate the language of plasticity in their writing (Sih, 2004; Foster, 2013a).

The difference in interpretation of the roles of behavior and morphology in evolution may lie in differences in two aspects of their expression: response time and reversibility. The probability that trait plasticity will evolve is inversely related to the time lag between exposure to a novel environment and expression of an appropriately responsive character (Moran, 1992; Padilla and Adolph, 1996; Thompson, 1999). Morphological phenotypes, once initiated, often develop along trajectories that are largely irreversible (see Ebert et al.,

${ }^{1}$ Department of Biology, Clark University, Worcester, MA, USA; ${ }^{2}$ Department of Biology, The College of New Jersey, Ewing, NJ, USA and ${ }^{3}$ Department of Biological Sciences, University of Alabama, Tuscaloosa, AL, USA

Correspondence: Professor SA Foster, Department of Biology, Clark University, 950 Main St, Worcester, MA 01610, USA.

E-mail: sfoster@clarku.edu

Received 5 December 2014; revised 2 June 2015; accepted 4 June 2015; published online 5 August 2015 
2014 for exceptions). Thus, responsiveness of morphological features to environmental transitions often incorporates a long lag time before a new phenotype can be realized, limiting the likelihood that phenotypic plasticity will evolve. In contrast, behavioral responses to changing environments appear to have evolved as first responders to environmental change in animals (and a number of other organisms), and are effective in this role because they are the products of constitutive physiological systems (for example, neural and endocrine) that can provide rapid, plastic responses to novel contexts (for example, Dukas, 2013; Snell-Rood, 2013). At one extreme, different behaviors can be quickly elicited by environmental context and are thus considered 'activational' (sensu Snell-Rood, 2013), exhibiting short time lags in expression and rapid reversibility.

This is of course, a contrast of extremes. Some clonal organisms exhibit relatively rapid morphological responses to changing environments (Tollrian and Harvell, 1999), and some non-clonal organisms can reverse the development of morphological structures (Ebert et al., 2014 for review). Equally, many behavioral phenotypes are the products of environmentally triggered developmental trajectories, or of extended periods of learning (developmental behavioral plasticity; Snell-Rood, 2013). As most efforts to contrast patterns of behavioral and morphological plasticity have concentrated on these extremes, a pattern of development, which we here term iterated developmental plasticity, has been largely overlooked, perhaps because life history phenotypes are not generally incorporated into comparative evaluations of patterns of plasticity across phenotypic categories. Iterated developmental plasticity is the case in which phenotypes develop repeatedly over the lifetime of a single individual, offering multiple opportunities for plastic modification of trait expression in response to changing environmental conditions.

The most obvious example of this phenomenon is iteroparity, in which reproductive characteristics can be modified between reproductive events within and between breeding seasons (JAB). Thus, behavioral and life history phenotypes of iteroparous animals that are associated with reproduction have the potential to exhibit significant iterative developmental plasticity, a pattern of plasticity that is less likely to apply to morphology than to other aspects of phenotype, although morphological features involving particularly dynamic tissues such as the brain, gills, and muscles may offer exceptions to this generalization (for example, Chapman et al., 2008; Crispo and Chapman, 2008; Tramontin and Brenowitz, 2000; Gonda et al., 2011a, b, 2013). Activational phenoytpes, predominantly behavioral or physiological phenotypes (Snell-Rood, 2013), also can be modified on varying iterative time scales, often over very short time frames. Activational behavioral phenotypes are examples of iterated phenotypes that often can be modified by experience (learning or learning-like processes). A behavioral or physiological response to environmental contexts, which is expressed repeatedly over the lifetime of an individual, permits repeated modification of expression in response to both fine and coarse-grained environmental variation. If such modification occurs, the trait is not only activational, but also exhibits developmental plasticity.

Because the lag time between perception of a cue, and the phenotypic response to the cue, are thought to be inversely related to the likelihood that trait plasticity will be favored (Moran, 1992; Padilla and Adolph, 1996; Thompson, 1999), trait iteration that occurs over relatively short time frames (for example, activational behaviors, multiple repeated events of clutch production within a season) could offer greater scope for plasticity than does trait iteration over longer time frames (for example, between years). On the other hand, phenotypes that are iterated say, between breeding seasons, could permit 'resetting' the within-season responses to environmental conditions. Here we evaluate these possibilities by contrasting the patterns of phenotypic plasticity across morphological, behavioral and life history trait categories in the adaptive radiation of the threespine stickleback fish, G. aculeatus. Like most fish, sticklebacks exhibit complex behavior and indeterminate growth (Wootton, 1976; Bell and Foster, 1994; Östlund-Nilsson et al., 2007 for reviews), and thus are excellent subjects for the study of plasticity. Because sticklebacks exhibit surprisingly little plasticity for some aspects of life history relative to other fishes (Baker et al., this issue), we will also contrast what we have learned about trait plasticity in stickleback with that in other species as appropriate. We hope this conceptual framework will facilitate classification of patterns of plasticity across trait categories and thus improve our understanding of the nature of plasticity, the way in which plasticity evolves, and ultimately, the contribution of plasticity to patterns of evolutionary change.

\section{THE ADAPTIVE RADIATION OF THE THREESPINE STICKLEBACK}

The threespine stickleback fish, G. aculeatus, is a small teleost with a Holarctic distribution. Oceanic fish, comprising both anadromous and marine life histories, have colonized coastal freshwater habitats repeatedly, giving rise to a remarkable freshwater adaptive radiation (Bell and Foster, 1994). As the last glaciers began to withdraw 12000 years ago (Mathews et al., 1970; Clague et al., 1982; Reger and Pinney, 1996), the most recent flush of colonization was initiated, producing a new wave of adaptive differentiation in deglaciated freshwater habitats (Bell and Foster, 1994; McPhail, 1994; Hohenlohe et al., 2010, 2012).

Oceanic populations are extremely large (Withler and McPhail, 1985; Cresko, 2000; Hohenlohe et al., 2010) and geographically uniform morphologically relative to their freshwater derivatives (Walker and Bell, 2000). The relative stability of the ocean habitat makes it unlikely that these populations have evolved substantially in the last 12000 years since giving rise to the most recent postglacial wave of colonization and radiation in fresh water. Thus, oceanic populations are likely to be reasonable surrogates for the ancestor that gave rise to postglacial populations within regions, although long-term evolutionary dynamics have produced regional structure in oceanic populations that make between-region generalization problematic (Orti et al., 1994; Johnson and Taylor, 2004; Hohenlohe et al., 2012; Foster, 2013b), which is particularly apparent in the Baltic Sea (DeFaveri and Merilä, 2013). The radiation is nevertheless unusual in that, with appropriate caution, regional oceanic populations can be used to infer ancestral character states relative to the postglacial freshwater radiation.

This radiation is also notable for high levels of parallelism, such that populations resident in similar freshwater habitats typically are similar in phenotype, even when clearly independently derived from oceanic ancestors. The association between phenotype and environment permits inference of adaptive value of particular traits (Bell and Foster, 1994; Foster et al., 1998; Schluter, 2000; Foster and Baker, 2004; Hendry et al., 2013) and, with the advent of sophisticated genomic tools, is facilitating our understanding of the degree to which parallel adaptive divergence reflects parallelism in the underlying genetic architecture of the traits (Hohenlohe et al., 2012; Jones et al., 2012a, b).

Ecotypic variation in the stickleback radiation has been examined in the greatest detail along two environmental axes; predation intensity and habitat-influenced foraging mode (the benthic-limnetic continuum). The former is relatively straightforward. Oceanic stickleback are almost uniformly heavily armored (although the Baltic Sea 
populations are unusually variable; Münzing, 1963; DeFaveri and Merilä, 2013). The armor comprises a set of posterior (lateral) plates and an anterior bony complex (Figure 1; central image). Loss or reduction in number of these plates in freshwater is common, and may be associated with low salinity, low calcium, enhanced swimming performance, and altered temperature or predation regimes (Reimchen, 1994; Barrett, 2010, for reviews). The anterior complex consists of the two anterior-most dorsal spines and a pair of pelvic spines all of which lock into place and are supported by an 'armor box' that consists of the pelvic girdle and anterior lateral plates (Figure 1: peripheral image at 12:00). The loss of the above complex may be facilitated by any of the above factors, and is clearly associated with the absence of native predatory fish (Bell et al., 1993; Bell and Ortí, 1994).

Differentiation along the benthic-limnetic continuum is primarily driven by differences in foraging mode in lacustrine habitats of different types. Juvenile threespine stickleback are largely planktivorous, a foraging mode retained by adults in some deep, steep-sided lakes (limnetic ecotypes). Limnetic fish exhibits traits adaptive for foraging on plankton in open water, including long, streamlined heads and bodies, and long, narrowly spaced gill rakers effective for straining small prey from the water. In shallower lakes with a more extensive littoral zone, reproductive individuals often reach larger sizes and shift to foraging on benthic invertebrates (benthic ecotypes). Benthic ecotypes possess a suite of morphological features suited to foraging for macroinvertebrates in structurally complex, benthic habitats, including deep body profiles, and relatively short heads and short, widely spaced gill rakers, which retain food particles in the mouth as water passes through to the gills (Hart and Gill, 1994; Walker, 1997; Aguirre, 2009; Willacker et al., 2010).

The shift to benthic foraging is also observed in oceanic fish on the breeding grounds. Benthic foragers, whether lacustrine or oceanic, forage in large groups and attack young in nests guarded by male stickleback if the nests are detected (Foster, 1994). In some populations they may destroy more than half of the nests with young (Foster, 1988). In benthic populations the conspicuous zig-zag courtship dance of limnetic males is rarely observed, and courtship is instead initiated by females, after which a behavior called dorsal-pricking ensues (Foster and Baker, 1995; Foster et al., 1998, 2008). This behavior is

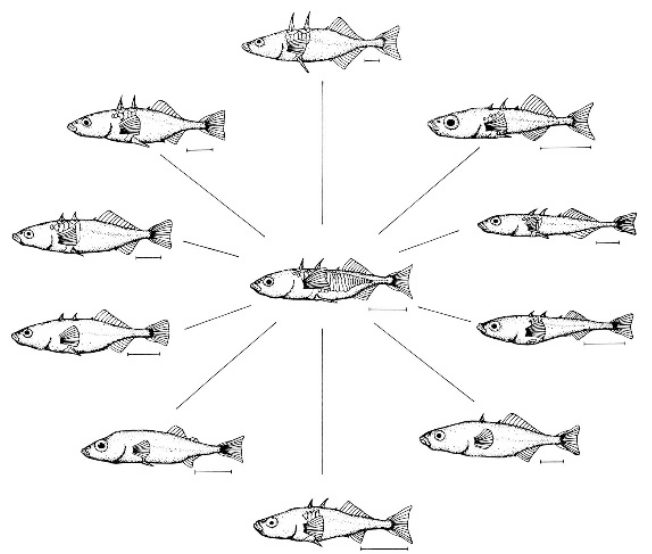

Figure 1 The adaptive radiation of the threespine stickleback, Gasterosteus aculeatus. The center image represents the oceanic type throughout most of the distribution. Peripheral images are freshwater derivatives that exhibit armor modification and loss as well as other changes in morphology. Bell and Foster, 1994, copyright open. less conspicuous than the zig-zag and apparently allows the males to survey their surroundings for risk (Sargent, 1982). In benthic populations, a complex diversionary display is often elicited by the approach of groups of conspecifics that, if effective, diverts the group from approaching the nest (Foster, 1988, 1994). In contrast, in extreme limnetic populations, males typically court females in approaching groups and the diversionary display is not seen (Foster, 1994, 2008; Foster and Baker, 1995). This pattern of ecotypic differentiation is apparent in behavior and morphology, but less so in life history, an issue we will address in the discussion (see also Baker et al., 2015).

\section{MORPHOLOGICAL PLASTICITY IN THE RADIATION}

Morphological plasticity is by nature developmental rather than activational. With few exceptions, plastic transitions in morphological features take time, tend to take place primarily during the transition from embryo to adulthood, and are rarely reversible (Ebert et al., 2014, and references therein). Adaptive morphological plasticity is less likely to evolve than is plasticity for many aspects of behavior, or some components of life history and physiology, simply because the time lag between detection of an environmental cue and a response to that cue is likely to be greater (Padilla and Adolph, 1996; Thompson, 1999).

This generalization largely holds for the aspects of phenotype that have been studied in the threespine stickleback. Most morphological features are constitutive. All sticklebacks have a shape, a jaw structure, an eye size. Ancestrally, they also possess substantial armor, consisting of lateral plates, a pelvic girdle and pelvic and dorsal spines. Some elements are expendable and, where it occurs, armor reduction is typically adaptive, facilitating escape from invertebrate predators and/ or providing growth advantages in fresh water (Reimchen, 1992; Barrett et al., 2008, 2009; Marchinko, 2009; Le Rouzic et al., 2011; Leinonen et al., 2011; Lescak and von Hippel, 2011; Lescak et al., 2012). Loss of spines and lateral plates occurs primarily via genetic change (Colosimo et al., 2004; Cresko et al., 2004; Shapiro et al., 2004; Coyle et al., 2007; Chan et al., 2010), although Loehr et al. (2012), while documenting heritability of plate number, demonstrated significant environmental and maternal effect influences on lateral plate expression as well. The origin of the environmental influence on plate expression is unclear, but appears not to be caused by salinity variation (McCairns and Bernatchez, 2012; Wund, unpublished).

Plastic influences on morphological phenotypes are more apparent in continuously varying characters including body size, body shape and gill raker morphology (Day et al., 1994; Wund et al., 2008, 2012 McCairns and Bernatchez, 2010, 2012), although genetic variation is a primary determinant of variation in expression of these traits (Peichel et al., 2001; Aguirre et al., 2004; Albert et al., 2008; McGuigan et al., 2010; Berner et al., 2014). Factors such as diet, habitat structure, water velocity and salinity vary considerably among populations, and all are known to impact the development of these features in stickleback and/ or other fishes (Day et al., 1994; Pakkasmaa and Piironen, 2000; Imre et al., 2002; McCairns and Bernatchez, 2012; Wund, 2012).

Research on morphological plasticity in stickleback has focused primarily on the possibility that initial (ancestral) patterns of plasticity in oceanic threespine stickleback have influenced the pattern of adaptation in the freshwater radiation, leading to the high levels of parallelism. That ancestral phenotypic plasticity could give rise to parallelism was initially suggested by West-Eberhard who titled it the binary flexible stem hypothesis (West-Eberhard, 2003). Consider an ancestral population that colonizes two discrete, alternative environments. Through plasticity colonists develop alternative phenotypes that then become increasingly adaptive through the process of 
evolution by genetic accommodation. Should this ancestral stem group repeatedly colonize similar habitats, plasticity will repeatedly reveal the same developmental variants, and selection should repeatedly refine them into similar adaptations, leading to widespread, parallel ecotypic variation.

This hypothesis was evaluated in the context of parallel evolution of benthic and limnetic lacustrine ecotypes. If the repeated evolution of these ecotypes resulted in part, from common patterns of developmental plasticity in ancestral colonists, modern oceanic stickleback should express benthic-like and limnetic-like traits when reared under conditions characteristic of those two environments. As predicted, threespine stickleback from an oceanic population reared on benthic versus limnetic diets exhibited patterns of plasticity that paralleled trophic differences between the benthic and limnetic phenotypes. Single limnetic and benthic populations reared on the two diets also exhibited expected patterns of plasticity, although the patterns of plasticity differed, suggesting genetic accommodation (Wund et al. 2008). Addition of habitat complexity to the benthic treatment produced additional differences in body form in the oceanic population that also paralleled patterns of ecotypic differentiation (Wund et al., 2012). Thus, these results clearly demonstrate morphological plasticity for trophic and body shape characteristics and they are compatible with a role for plasticity in the origin of benthic-limnetic parallelism in the freshwater radiation.

Although the traits we examine here are unlikely to exhibit true reversal in the sense that they could be progressively lost, or regress, the developmental trajectory can be modified as late as 4 months of age. In this instance, oceanic (ancestral) stickleback were raised in the two environments described above (including benthic complexity), but half of each group were switched between environments at four months of age (the other half of each serving as controls). One month later, individuals experiencing a treatment shift displayed identical and intermediate morphological phenotypes relative to those that had remained in their original environments, suggesting that they were undergoing shape reversal via developmental morphological plasticity (Figure 2). Thus, it appears that developmental trajectory alteration can offer a plastic phenotype 'rescue' in response to changing environmental conditions even for morphological traits typically considered to exhibit relatively low plasticity. Given that stickleback exhibits indeterminate growth, plastic readjustment of morphology may have an iterative nature in populations of threespine stickleback that live multiple years, and which thus may encounter annual shifts in resource availability during the primary growing season.

A final class of 'morphological' features are those consisting of physiologically active tissues that tend to exhibit considerable plasticity. Examples include muscles that respond to use, and gill tissues that respond to hypoxic conditions (for example, Chapman et al., 2008; Crispo and Chapman, 2010). Although these traits have not to our knowledge been studied from this perspective in stickleback, it is likely that some of the shape changes described in Wund (2012) involve muscle plasticity. Neural tissue is also highly responsive to environmental conditions, a responsiveness that has been detected in brains of both the threespine stickleback and the ninespine stickleback (Pungitius pungitius). In the ninespine stickleback, the size of the bulbi olfactorii (chemosensory center) was influenced by rearing regimes (feeding and predation) in two populations of freshwater fish, but not in marine (ancestral) fish (Gonda et al., 2011b). In the threespine stickleback, telencephalon size decreased substantially after wildcaught fish were moved to the laboratory, and telencephalon shape changed to become more like that of laboratory-reared fish over a 90day period (Park et al., 2012), suggesting not just plasticity but reversibility. Thus, the brains of stickleback could undergo iterative developmental shifts, possibly on a seasonal basis.

A more obvious set of physiologically active tissues that can undergo iterative developmental modification are those that regress but then are redeveloped during the breeding season. In stickleback, these

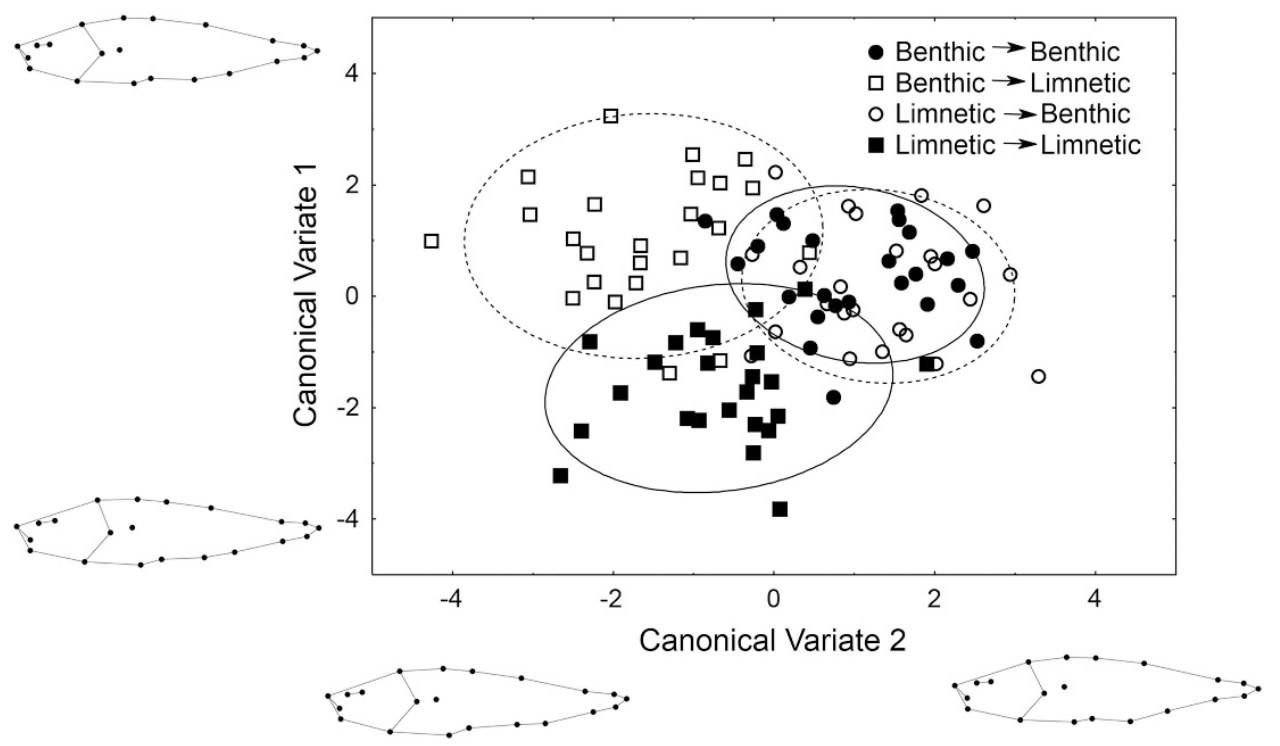

Figure 2 Canonical variates analysis on body shape of anadromous stickleback reared under four conditions: BB fish were in a 'benthic' habitat/diet treatment for 5 months; LL fish were in a 'limnetic' habitat/diet treatment for 5 months; BL fish experienced benthic conditions for 4 months, followed by 1 month in the limnetic treatment, and LB fish experienced limnetic conditions for 4 months, followed by 1 month in the benthic treatment. CV 2 represents shape differences along the typical benthic-limnetic axis, with BL and LB fish intermediate to the BB and LL morphologies. These data suggest that BL and LB fish were in the process of a morphological reversal when they were killed. Permutation tests were used to determine whether body shape differed significantly among pairs of groups, and only BB and LL were significantly different $(P=0.05$; all other $P>0.09)$. 
include testes (Schneider, 1969), and even sperm (Mehlis and Bakker, 2013), as well as ovaries and the male kidney, which becomes elaborated during the breeding season to produce spiggin, the glue used by males during nesting (Borg, 2007, for review). Though these structures are not traditionally considered morphological, they offer a useful contrast with less-plastic aspects of morphology, and clearly offer evidence of iterated developmental plasticity of morphological features, an observation made early by Tinbergen (below).

\section{BEHAVIORAL PLASTICITY IN THE RADIATION}

As far as innate behavior is concerned, development can be considered complete when the animal reaches maturity. But it should be realized that this stage is not reached by all behavior patterns at the same time. Most of them, usually the non-reproductive patterns of the adult individual, complete their development at an early stage, whereas the reproductive patterns appear much later. Moreover, they subsequently regress and redevelop repeatedly, at least in many species, and the phenomenon deserves no less attention than the development of the other activities. Niko Tinbergen, (1951) p. 129.

This passage could serve as an introduction to the concept of the iterative modification of phenotypes we emphasize here. This is particularly true as Tinbergen then progresses to the modification of these phenotypes via learning, an intrinsically plastic process. Unquestionably, the classical ethologists, primarily responsible for raising the threespine stickleback to the status of a model species in behavior, understood the interface between genetic (innate) and plastic contributions to behavior. They further were aware that highly stereotyped, innate behaviors varied in performance even within individuals, reflecting this environmental responsiveness (for example, Barlow, 1977).

As an example, the zig-zag motor pattern exhibited by males during courtship was clearly recognized as an innate behavior, as males that have never observed a zig-zag dance perform the behavior in response to either a female or a model of a female (Tinbergen, 1951; Rowland, 1994 for reviews). However, the same males, when presented with a male 'intruder', or a male dummy, will attack the dummy. These behaviors were generally viewed by those who studied them as mutually inhibitory, and causally linked, as territorial intruders immediately induced increased male aggression and decreased courtship toward females, a pattern that gradually reverses itself in the absence of intruders (for example, Tinbergen, 1951; Wilz, 1972). Recent evidence of a shared neural network underlying social behavior, including aggressive and reproductive behavior in fishes and other vertebrates (for examples, Goodson, 2005; O'Connell and Hofmann, 2011), suggests that these alternative but linked behaviors may well be the products of an activational neural system, as shared components are likely to be involved in the production of alternative behavioral responses.

This example is particularly instructive because there is evidence of both immediate, activational responses to alternative stimuli, and a slower return to courtship following an aggressive challenge. The temporal difference in response is likely adaptive, as the territorial challenge poses an immediate threat, requiring an immediate behavioral response, whereas the recovery period reflects assessment of declining risk with time since presentation of the threat. Failed courtships, in which females attempt to enter the nest but then leave without spawning, can also result in immediately enhanced aggression toward females, and elevated levels of nesting activity with a slow recovery of active courtship (Wootton, 1976; Rowland, 1994 for reviews). In the latter case, the slower recovery could reflect the need for nest repair following partial or complete entry of the female. An alternative to the adaptive explanations in both cases is that the longer recovery relative to the initial response reflects the time required to revert to the original genomic/hormonal (motivational) state following the initial stimulus - an intriguing direction for future research.

Sneaking behavior by males offers similar evidence of short-term 'developmental' elements of activational responses to specific environmental contexts. Males in at least some populations in Europe (for example, van den Assem, 1967; Goldschmidt et al., 1992), Eastern North America (de Fraipont et al., 1993) and Alaska (Shaw and Foster unpublished), build nests and then shift to sneaking behavior. Sneakers assume a mottled drab pattern, desert their nests and swim widely until they detect courtship, at which time they drop gently to the substratum and move slowly to the nest of the courting male using rocks and plants as cover. Successful sneakers enter the nest as the female leaves, and immediately return to the nest entry to steal eggs, which they place in their own, often derelict nests. They may return to steal eggs more than once, following which they assume bright coloration and court females (Östlund-Nilsson, 2007 for review). Later-nesting, often younger males are more likely to sneak than are earlier-nesting older males in several populations (Goldschmidt et al., 1992; de Fraipont et al., 1993), a suggestion that conforms to our field observations in Alaskan populations. If true, older males that have been through one breeding season as sneakers may be those that nest first, and court actively, whereas first-time breeders more often sneak. Sneaking could thus offer an example of iterative behavioral development in which the development of sneaking is most likely in breeding seasons early in life, becoming less likely as the males age. Oddly, sneaking behavior during courtship is not observed in freshwater populations in southern British Columbia, Canada, a condition that likely reflects either a loss of plasticity, or a shift in expression threshold in this region relative to the rest of the distribution of threespine stickleback (Goldschmidt et al., 1992; Shaw, 2014).

This regional difference in sneaking tendency highlights a characteristic of the threespine stickleback radiation that makes it an outstanding subject for evolutionary research: population variation that includes variation in behavioral plasticity among populations. This is evident in courtship behavior as different populations exhibit different tendencies to perform the zig-zag dance, versus the less conspicuous dorsal-pricking behavior often initiated by females (Wilz, 1972). A contrast of courtship behavior in natural contexts with that observed in the laboratory illustrates this point. Oceanic (ancestral) populations are variably exposed to cannibalistic foraging groups that attack nests and consume young within them. Males in the wild rarely incorporate the conspicuous zig-zag dance in courtship in the field when foraging groups are abundant, but do so more often when foraging groups are absent (Foster, 1995; Foster et al., 1998), and under laboratory conditions (Figure 3; Shaw et al., 2007). In benthic populations, cannibalism is nearly ubiquitous, and males from two populations retain ancestral patterns of plasticity, but are less likely to perform the zig-zag dance, suggesting evolution of the norm of reaction from the ancestral state (Figure 3). In contrast, in the historically limnetic Lynne Lake population, the zig-zag dance was a consistent part of courtship both prior to the emergence of cannibalistic foraging groups, and several years after such groups were first detected, indicating a loss of sensitivity to the presence of foraging groups (genetic assimilation).

Courtship behavior thus is clearly plastic, and activational in all populations, in that all populations have the capacity to perform both the zig-zag dance and dorsal pricking, but the tendency to do so has 


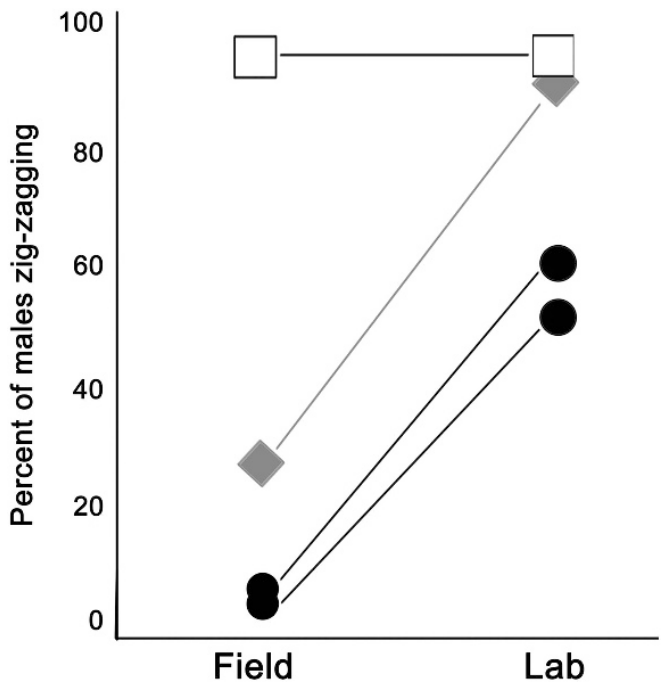

Figure 3 The proportion of courtships by males from four Alaskan threespine stickleback populations that incorporated or failed to incorporate the zig-zag dance in field and laboratory environments. Only the first courtship per male is included. Cannibalistic groups are present in the field in benthic (black circles) and oceanic (grey diamonds) populations. Although historically absent from the limnetic Lynne Lake population (squares), cannibalistic groups, and male diversionary responses are now common, but the frequency courtships incorporating the zig-zag dance in the field is unchanged (Chock, 2008). Figure adapted from Shaw et al., 2007.

evolved. In the historically limnetic Lynne Lake population, sensitivity to the presence of benthically foraging cannibalistic groups has either been lost, or the threshold has shifted over the 12000 years in which paternal defense of nests was unnecessary (Chock, 2008). That a shift in threshold is plausible is indicated by the greater stimulus intensity required to elicit the diversionary display in laboratory-reared males from limnetic (non-cannibalistic) versus benthic or oceanic (cannibalistic) populations (O’Neil, 2012). This is a conspicuous display that diverts the attention of approaching cannibalistic groups from the nest to the male. The behavioral response of males to cannibalistic groups is clearly activational in that males respond to groups with the display only in response to a direct approach by a group, otherwise joining or watching groups that are passing by or are above (Foster, 1988). Although this display is never seen in response to the approach of groups in non-cannibalistic populations (Foster, 1994), it can be elicited from limnetic, laboratory-reared males (three populations) when groups trained to attack nests do so (O’Neil, 2012). This behavior has re-emerged in the Lynne Lake population that is reverting to ancestral cannibalistic tendencies (Chock, 2008). Evidence to date suggests that the form of the diversionary display is activational in that it is an immediate response to precise environmental context, but also that the sensitivity to context can evolve.

Recently, interest in persistent individual variation in behavior and in persistent suites of correlated behaviors (personalities or behavioral syndromes sensu (Dall et al., 2004; Sih et al., 2004a, b) has gained traction as a theoretical issue in the evolution of behavioral phenotypes. Particularly well studied in the context of individual variation within and between populations is the shy/bold behavioral continuum (Huntingford, 1976; Wilson et al., 1994; Bell and Sih, 2007; Dingemanse et al., 2007). The origins of these differences are not well explored to date, although there is evidence for both genetic and learned contributions in threespine stickleback (Bell and Stamps, 2004; Bell and Sih, 2007; Dingemanse et al., 2007; Wund et al., 2015), and one experimental study provided clear evidence that experience with predators could organize syndromes (Bell and Sih, 2007). Whether behavioral syndromes that present as a consequence of experience are persistent or reversible has not to our knowledge been examined, although the experiment by Bell and Sih (2007) makes clear that the organization of such syndromes is activational in that presumably the same neural network can produce alternative outcomes over relatively short time frames.

As the fish in these studies were wild-caught, the results are sufficient only to indicate that antipredator and associated behavior can be modified by experience. However, a recent comparison of the antipredator responses of laboratory-reared and wild-caught threespine stickleback from Alaskan freshwater populations with and without rainbow trout (Oncorhynchus mykiss) predation demonstrated that stickleback from three predator-free populations responded more weakly to a simulated trout attack than did stickleback from populations with trout, whether those trout were native to the lake (three populations) or recently introduced (three populations). Although these behavioral differences among populations were generally maintained in laboratory-reared fish, laboratory-reared (predator-naive) fish from some populations showed substantially reduced antipredator responses relative to their experienced, wild-caught counterparts (Wund et al., 2015). Thus, it appears that the expression of antipredator behavior can be influenced by the history of selection and evolutionary responses to that selection, but that expression also can be modified by experience (activational or developmental plasticity) in at least some populations. In no case has decay (reversal) of developmental effects on antipredator behavior been examined in adult stickleback.

In contrast, embryonic learning of predator cues, as indicated by the behavior of the fry they produce, appears to decay in an adaptive fashion (reversible). Stickleback embryos (laboratory crosses) exposed to olfactory cues from predators (sculpin) that have been fed stickleback eggs exhibit stronger antipredator responses to cues from the predators alone than do control fry. Similar responses are elicited from fry exposed to cues from stickleback that have cannibalized embryos when exposed to cues from adult stickleback not fed embryos, but this response decays more rapidly than does that to heterospecific predators, disappearing at a size at which fry are no longer vulnerable to cannibalism (Golub, 2013). In this instance, behavioral responses to predators are not only activational as they are triggered by detection of a predator, but also are developmental and in some cases, reversible.

Perhaps the ultimate form of developmental phenotypic plasticity involves maternal or epigenetic effects on offspring (Hallgrímsson and Hall, 2011; Love et al., 2013 for reviews). Although the mechanisms are not well understood, there is emerging evidence that, as has been demonstrated in mammals, maternal stress can impose epigenetic influences on offspring behavior in fish with external fertilization (McCormick, 1998; Giesing et al., 2011; Roche et al., 2012; Mommer and Bell, 2013). In stickleback, the stressor most often studied is exposure to a heterospecific predator. Recent research indicates that repeated exposure to a model predator can cause changes in egg characteristics (higher cortisol levels, larger size and initially higher metabolism; Giesing et al., 2011), has variable effects on offspring antipredator behavior (Giesing et al., 2011; McGhee et al., 2012), can reduce offspring survival (McGhee et al., 2012) and can have a negative influence on performance in a learning discrimination task (Roche et al., 2012). These epigenetic modifications of offspring behavior are likely to be induced by the glucocorticoid stress response of the mother, which could in turn affect responsiveness of this system in offspring, although results to date are equivocal (Mommer and Bell, 

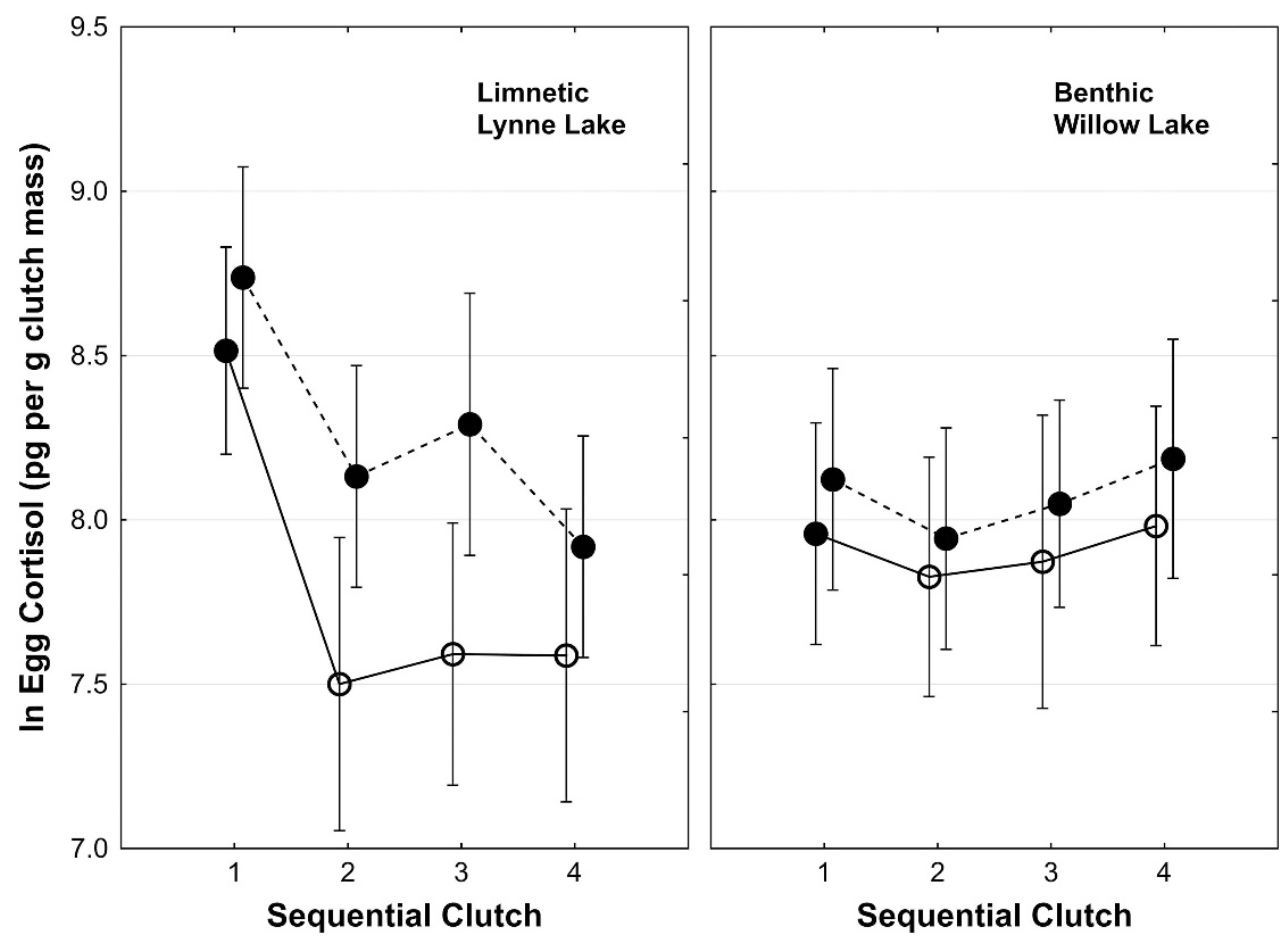

Figure 4 Variation in cortisol concentrations of successive clutches extruded from female threespine stickleback (Gasterosteus aculeatus) after prolonged $(24 \mathrm{~h}$; open circles) or short ( $<8 \mathrm{~h}$; closed circles) post-ovulatory egg retention. A two-way repeated measures ANOVA indicated nonsignificant effects of population or population by treatment. Hormone concentration of clutches differed between short and prolonged treatment in the limnetic population but not in the benthic (contrast: $P<0.001$ ).

2013, 2014). Effects such as these are clearly developmental in nature, and such studies begin to address the physiological underpinnings of phenotypic plasticity.

Cannibalism also has the potential to impose maternal stress because the threat of cannibalistic attacks deters males from courting effectively as they instead defend nests from intruders, leading to protracted post-ovulation egg retention by females in benthic populations where cannibalism is a consistent threat (Foster and Baker, 1995; Foster et al., 1998, 2008). Ovulation itself is stressful, an observation confirmed with data on opercular beat rates in one benthic and one limnetic population (post-ovulatory beat rates greater than preovulatory; F1,16=43.3, $P<0.0001$; Mazzarella, 2010). Laboratoryreared limnetic females are more likely to drop clutches than are benthics when forced to hold eggs $24 \mathrm{~h}$ post ovulation (78\% versus $40 \% ; P=0.012)$. Both ecotypes are more likely to drop clutches when forced to hold eggs for $24 \mathrm{~h}$ than within $8 \mathrm{~h}$ post ovulation (pooled frequencies $55 \%$ versus $10 \%$; $P=0.0001$ ). Data on egg cortisol levels suggest that limnetic and benthic females respond differently to forced egg retention, assuming that egg cortisol is a good proxy for maternal circulating cortisol levels (Figure 4). The high values for Lynne Lake first clutch eggs are likely caused by greater responses of limnetics than benthics to handling (movement from home tanks to isolation tanks prior to the first clutch). Focus on clutches 2-4 suggests little difference between clutches or treatments, especially for benthics. However, limnetics show reduced cortisol levels when forced to retain eggs. A possible explanation is that, because selection has favored clutch release in limnetics, and because spawning delays are rare, egg retention is distressing for limnetics. This could lead to negative feedback inhibition whereby high maternal circulating cortisol levels shut down the neuroendocrine stress axis as a protective mechanism against the damaging effects of chronic stress. This, then, is reflected in low egg cortisol levels. Benthics, which are persistently required to hold eggs for extended periods, may have evolved lower baseline cortisol levels, or less marked increases in cortisol when forced to retain eggs. Because benthics do not experience chronic stress axis activation, they may not invoke negative feedback inhibition and, therefore, maintain higher maternal circulating cortisol, which is then reflected as moderate egg cortisol levels. These are alternatives that remain to be explored. These last examples clearly bridge elements of behavior with life history, and offer examples of iterative developmental plasticity, a form of plasticity particularly common in stickleback life history traits.

\section{FEMALE LIFE HISTORY PLASTICITY IN THE RADIATION}

Life history traits are arguably the class of traits most closely linked to fitness as they include, for example, the timing of reproduction within the life cycle, the overall effort put into reproduction, the partitioning of that effort into the number and sizes of propagules, and the frequency of reproduction both within a season and across breeding seasons (Reznick et al., 2000). These traits are typically influenced by resource-based trade-offs, and thus are expected to be responsive to environmental exigencies. As expected, a strong plastic component to variation is commonly observed (Mousseau and Fox, 1998; Nylin and Gotthard, 1998). This is particularly evident in the case of female life histories in iteroparous organisms such as the stickleback, in which reproductive plasticity can be expressed in each of the traits listed above, across a broad range of time scales. Thus, the multi-level iterated nature of reproduction offers great flexibility in adjusting the overall allocation of resources.

As in the case of morphology, many life history traits can be considered constitutive in that individuals have a size at first reproduction, in each reproductive season or event they have a testis 
or ovary size, and in females, a clutch size and egg size, and a withinseason clutch frequency/number. Again like morphology, variation in life history traits reflects underlying genetic differences (Mousseau and Roff, 1987), but they tend to exhibit greater and more rapid environmental responsiveness than does morphology. To the extent that life history traits are environmentally responsive and iterated in expression, the opportunity exists for adaptive plastic modification of the phenotype within and between reproductive seasons, although the time frame will be longer than that for behavior, which primarily is activational and readily reversible.

The size or age at which females become reproductive (maturation) has a significant impact on future potential reproduction, particularly in taxa that exhibit indeterminate growth, as the initiation of maturation often exacts a growth cost (Stearns, 1992; Charlesworth, 1994; Roff, 2000). This is likely to be particularly important in species that reproduce on a strongly seasonal basis in a limited number of years. Plasticity of maturation has been documented in a diversity of fish (for example, Barot et al., 2004; Morita and Fukuwaka, 2006), and can be cued by early life growth rate (Bertschy and Fox, 1999; Auer, 2010) or size at the onset of the breeding season (Charnov, 1990; Reznick et al., 1990; Day and Rowe, 2002). Reproduction early in life is generally thought to be favored due to reproductive 'compounding' (Caswell, 1989; Roff, 2000; Angilletta et al., 2004), a factor that may have served to maintain plasticity in expression of this trait in threespine stickleback in which age/size at first reproduction is heritable (McPhail, 1977; Snyder and Dingle, 1989; Snyder, 1991). Threespine stickleback most often appear to breed first at age 2 (Baker et al., 2008), but in most freshwater populations an annually variable proportion breed in year 1 (Baker et al., 2015), and these are generally the largest age-1 fish, though they can be induced to breed as early as 200 days of age in the laboratory (Snyder, 1991). Oceanic (ancestral) populations breed primarily at age 2 in Alaska, but also show a variable proportion of age-1 breeding females. Thus, age and size of first reproduction is apparently an anciently plastic trait in the stickleback radiation. This plasticity is likely to have been favored in freshwater by the rather wide range of breeding dates within many populations, causing seasonally late-hatching individuals to delay reproduction for a year relative to those hatching early in the season (Saito and Nakano, 1999; Baker et al., 2015). As maturation is a onetime event, reversibility, or iteration are not relevant except in the sense that a female could potentially reproduce in 1 year and then skip reproduction in a later year (for example, Trippel and Harvey, 1989), although this seems unlikely in fish with lifespans that encompass only two breeding seasons ( 3 years of life) in most populations.

In iteroparous organisms, investment in reproduction (reproductive effort) can undergo plastic modification both between clutches within breeding seasons, and between breeding seasons. Such plasticity has been documented in a wide range of ectotherms (for example, Gotthard and Nylin, 1995; Nylin and Gotthard, 1998; Poizat et al., 1999; Brown and Shine, 2007). The most common metric of reproductive effort is the mass of eggs in a single clutch, scaled to body mass (for example, Gunderson and Dygert, 1988; Heins and Baker, 1993).

Females in many populations of threespine stickleback have ample opportunity to adjust reproductive effort as a female can produce 8-9 clutches in a season (Wootton, 1973; Wootton and Fletcher, 2009; Baker, unpublished), and in some cases can reproduce in 2-3 seasons (Baker, unpublished). In some populations, females are capable of producing more than twice their body mass in eggs. Despite the opportunity for adjustment of clutch mass within seasons, available evidence suggests that females set size-appropriate clutch mass well before reproduction is initiated, and then maintain that clutch mass throughout the breeding season (Baker et al., 2015). Under conditions of reduced rations, it is the inter-clutch interval rather than effort per clutch that shifts, lengthening after production of the first low-ration clutch. It thus appears that plastic adjustment to inter-clutch interval is responsible for within-season accommodation of reproductive effort to altered nutrient intake (Ali and Wootton, 1999; Wootton and Fletcher, 2009), and that it is relatively rapidly developmental in nature. This plasticity may simply reflect the inability to produce a clutch quickly when food is scarce, or it may be protective of body organs, insuring that they are not too severely depleted for survival into future reproductive seasons to be possible (Baker et al., 2015).

Although there is little evidence for adjustment of clutch mass within seasons, comparison of laboratory-reared and wild-caught individuals from the same populations offers evidence of clutch mass plasticity in that laboratory-reared females develop smaller relative clutch masses than do their wild counterparts. This effect is most prominent in freshwater populations where females are likely to be able to spawn in more than one breeding season. Thus, it is plausible that freshwater stickleback in good condition (that is, in the laboratory) reduce reproductive effort in a way that could increase the probability of reproducing in future breeding seasons under natural conditions. The effect is smaller in oceanic populations where females are very unlikely to spawn in $>1$ year, suggesting that the ancestral condition is one of low plasticity for annual adjustments in clutch mass.

Given this information, the presence of iterative developmental plasticity in relative clutch mass across years is perhaps not surprising. Data from field collections indicate that in the majority of populations studied by Baker et al. (2015), females increase their size-adjusted reproductive effort as they move through sequential breeding seasons. This suggests that females are not reproducing at maximum (though perhaps still very high) values early in life, likely enhancing the probability of surviving into future reproductive seasons, and that they allocate greater proportional resources to reproduction as the probability of surviving to another breeding season declines. Thus, this pattern suggests iterative, adaptive developmental plasticity for this trait. Baker et al. (2015) suggest that the clutch mass to body mass ratio of a given population can perhaps be viewed as the constitutive expression of reproductive effort-and that females modify this effort plastically as they enter a breeding season based on condition and environmental cues. This is an intriguing way of thinking about the interface between constitutive (heritable) contributions to populationspecific aspects of life history.

Egg size in fishes typically is considered to be under strong selection (Bernardo, 1996), particularly as it tends to be correlated with the size and capabilities of the fry (Kingsolver et al., 2001; Einum and Fleming, 2002; Segers and Taborsky, 2011). Egg or offspring size plasticity is common in many animals, including fish, and has been studied in detail (Rodd et al., 1997; Trexler, 1997; Kolm, 2001; Abney and Rakocinski, 2004; Leips et al., 2013). Stickleback are unusual in that they exhibit relatively little plasticity for this trait within breeding seasons. That which has been detected seems for the most part, not to be adaptive, but rather to be an extreme response to inadequate nutrition (Baker et al., 2015, for review). However, some potentially adaptive egg size plasticity has recently been suggested in a few Alaskan populations subjected to high levels of parasitism by the cestode Schistocephalus solidus (Heins et al., 2014). There is also evidence of iterative developmental plasticity for egg size on an annual basis in many freshwater populations and all oceanic populations that have been studied (Baker et al., 2015). The plasticity is expressed as a 
positive relationship between egg size and female size or age in crosssectional data, suggesting that individual females may increase egg size with increasing body size or age, a hypothesis that remains to be demonstrated directly in individual females. This apparently ancestral trait is only exhibited in about half of freshwater populations, however, suggesting that many populations may have lost this plasticity.

Clutch size is the number of eggs into which reproductive effort is subdivided. Because clutch size is clearly a fundamental life history trait, and because it can be more easily quantified in many species than can reproductive effort, clutch size has been studied in a wide range of species. As a byproduct of these efforts, clutch size plasticity has been documented across a wide range of taxa including many fish (Kennedy et al., 2007; Kindsvater and Alonzo, 2014). However, there appears to be little within-season plasticity of clutch size in stickleback. Clutch size is tightly associated with reproductive effort (population level correlations range from $0.79-0.90$ across 83 populations; Baker et al., $1998,2008,2015)$ and both are strongly influenced by female size. Once the effect of female size is removed, clutch size and egg size are inversely related, exhibiting expected trade-offs (Baker et al., 1998, 2005, 2015; Oravec and Reimchen, 2012). Between-season plasticity in clutch size has been documented in stickleback but it is so tightly linked to reproductive effort and egg size once adjusted for female body size that individual values are highly constrained, rendering the driver of plasticity unclear (Baker et al., 2015).

Overall, life history traits of female stickleback appear to exhibit surprisingly modest plasticity and essentially no reversibility. Within seasons, plasticity is primarily exhibited in shifting inter-clutch intervals as conditions change, or possibly as the season progresses. Between-season plasticity (iterative developmental plasticity) is apparent in modifications of body size-adjusted reproductive effort, egg size, and clutch size in many but not all populations. Oceanic (ancestral) fish exhibits plasticity for onset of maturation, a characteristic retained by most freshwater populations, whereas comparisons of reproductive effort in oceanic and postglacial freshwater populations suggest that low plasticity for this trait was the ancestral condition, but that plasticity has tended to increase over the course of adaptation to freshwater. Even given the apparent modest plasticity in individual traits, the multivariate life history expressed over the entire lifespan may compensate by providing a variety of means to respond plastically to the environment (Figure 5).

\section{DISCUSSION}

As anticipated, different classes of phenotypes exhibit different patterns of plasticity in threespine stickleback. Morphological features, traditionally considered those underlain by cartilage and bone invertebrates, are largely irreversible once formed, and do not exhibit iterative development in the sense that the development of the trait can be reversed or initiated de novo more than once in an individual's life. However, at least as juveniles, threespine stickleback shifted from benthic to limnetic environments (or the reverse) are able to alter developmental trajectories in a habitat-appropriate manner, and the patterns of plasticity have been demonstrated to mirror the greater evolutionary divergence between benthic and limnetic ecotypes, suggesting that plasticity could have influenced the patterns of evolutionary change in the freshwater adaptive radiation (WestEberhard, 2003; Wund et al., 2008, 2012).

Organs less traditionally considered in the context of shape, physiologically active soft organs that do not lay down extracellular matrices like cartilage or bone, can be more readily modified in response to seasonal changes or shifting environmental conditions.

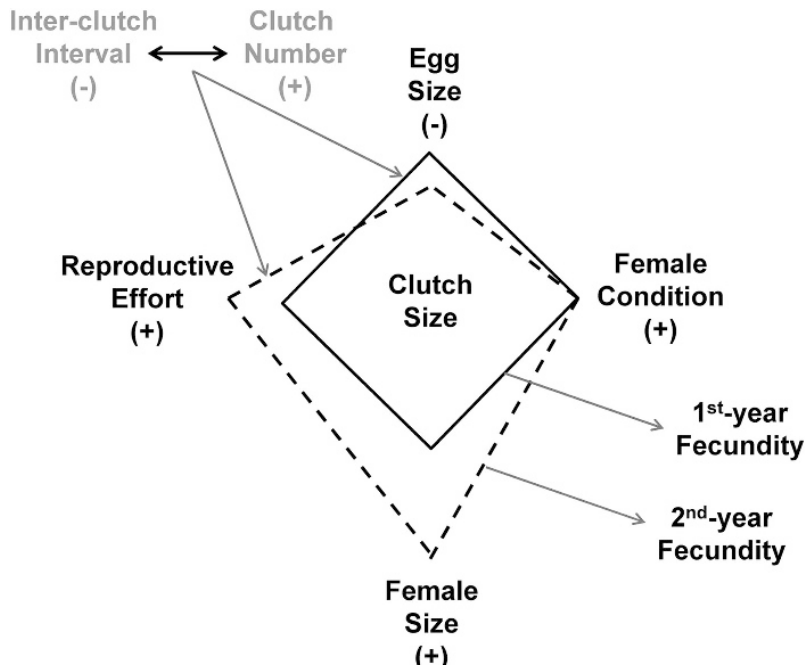

Figure 5 Interrelationships among female life history traits for a generalized threespine stickleback population in which females are able to breed in two consecutive years. In this model, clutch size is the trait of central importance, as it represents the maximum potential successful offspring per spawning; other traits collectively alter the clutch size. The female's 1st-year clutch size is indicated by the solid lines forming a diamond. The females plastically alter their pattern of investment in the 2 nd year, indicated by the dashed lines forming a distorted diamond. In her 2nd year the female is larger, which increases clutch size substantially; she makes an increased reproductive effort, which also increases clutch size; in contrast, she makes larger eggs which diminish clutch size; condition is unchanged. The size of each diamond is directly proportional to clutch size, and the reallocation strategy is indicated by the change in the diamond's shape. In both years, ration variation drives changes in the inter-clutch interval and in the total number of clutches; this would be visualized as multiple diamonds extending along a time axis within each breeding season.

Environmentally responsive tissues, including the brain, can exhibit patterns of plasticity that can result in changes in both size and shape (above). As a number of plastic organs (kidneys, gonads) are associated with reproduction, often an iterated event both within and between seasons in stickleback, these transitions, at least at an annual level, tend to be linked to iterated events in life history.

Plasticity of life history traits in female threespine stickleback is surprisingly more similar to that displayed by 'hard tissue' morphological traits than it is to activational behavioral traits. For example, stickleback do not appear to have the ability to make rapid, adaptive changes in clutch size or egg size. Instead, within-season changes are rather extended and subtle shifts, and these shifts are only made if conditions (for example, ration level) are altered for a relatively long period of time. However, life history plasticity also shows some substantive differences from that shown by morphology. Most divergently, female stickleback appear to plastically determine an overall life history strategy (for example, set appropriate levels for individual traits) well before the reproductive season commences, and then follow their set strategy for an entire season, except when conditions change substantially after reproduction begins. As a consequence of this, life history plasticity is only apparent when viewed across the entire adult lifespan. This plasticity, which Baker et al. (2015) have termed 'iterative ontogenetic plasticity' is typically exhibited as a shift in allocation trajectories relating life history traits to body size and age. For example, in many populations, including all ancestral populations studied to date, egg size increases with size and/ or age, and also in many populations the level of reproductive effort 
increases with size and age. This suggests that the target level for each trait is reset annually, likely cued by factors intrinsic to the female herself-body size or energy state are plausible candidate factors.

The expression of some aspects of behavior, especially reproductive behavior, is tightly linked in temporal expression to life history, and similarly offers the opportunity for iterated development (reproductive bouts within a season or reproduction between seasons) that can potentially lead to quite different phenotypes among iterations (for example, sneaking or territorial behavior). The low plasticity of life history traits within seasons suggests that this connection should not strongly influence behavior, though we know so little about individual behavioral or life history trajectories within or between seasons that such relationships are very difficult to evaluate. As anticipated, most aspects of behavior, particularly those involving specific motor patterns, are both activational and reversible. As these behaviors can be elicited repeatedly during the lifespan, but are not performed identically among iterations, they can be interpreted as exhibiting short-term iterated developmental variation as well (often via learning). Activational phenotypes are likely to be limited to behavioral and some physiological responses to environmental cues (Snell-Rood, 2013).

Although we have emphasized behavioral phenotypes that include activational and developmental components, research in behavioral ecology has generally focused on the ability of animals to respond adaptively, on very short time scales, to changing environments (for example, Krebs and Davies, 1993; Stephens et al., 2007; Westneat and Fox, 2010). This is particularly evident in studies of optimal foraging in which threespine stickleback (and many other species, ibid) have been shown to respond rapidly and adaptively to changing foraging conditions (Milinski, 1988; Hart and Gill, 1994), or with a short delay in patch switching that is clearly adaptive and does not seem to reflect developmental delay (Laskowski and Bell, 2013). This kind of behavior, which responds rapidly to environmental context, is clearly activational and rapidly reversible. These studies have generally focused on single freshwater populations however, and it is unclear how broadly they extend across populations in the freshwater radiation.

There can be little question that the overriding story of the stickleback radiation has been one of the high level of parallelism in the freshwater radiation, coupled with our ability to infer character polarity relative to carefully selected regional oceanic populations. Parallelism in morphology and behavior has been widely reported along the benthic-limnetic continuum (for example, Lavin and McPhail, 1986; Walker, 1997; Willacker et al., 2010) and with respect to levels of predation in Scotland and Alaska (Reimchen, 1994; Barrett, 2010, for reviews). The apparently high levels of parallelism in morphology and behavior could have very different underlying causes, in part due to the differing kinds of plasticity generally exhibited by the two classes of traits. In the case of morphological divergence along the benthic-limnetic axis, the transition from reliance on planktonic foods while in the ocean, to foraging on benthic invertebrates during migration to freshwater-breeding grounds, could have maintained an ancestral binary flexible stem, facilitating parallel divergence in freshwater (Wund et al., 2008, 2012), as well as the reversible developmental trajectories reported here. It is also possible, however, that there may be very few ways to modify the ancestral trophic apparatus to function effectively in the two foraging contexts. In this case morphological and plastic (binary flexible stem) starting points, combined with functional constraints, could have imposed the high levels of parallelism in morphology along the benthic-limnetic axis.
In contrast, the cause of parallelism in behavior may lie in the presence of a constitutive neural network that possesses an ancestral response axis to conditions in benthic and limnetic environments, or low- and high-predation environments, that can be readily modified in degree of responsiveness, though not so easily in the pattern of response. The behavioral (activational) motor patterns, and their responses to external triggers that have contributed to ecotypic divergence, appear to be ancestral and largely modified not by altering the pattern of the behavior, but rather by alteration of the sensitivity of the plastic (activational) response to stimuli. In the case of the benthic-limnetic contrast, variability of conditions on breeding grounds experienced by oceanic stickleback may have established an essentially binary flexible stem that predisposed behavioral phenotypes to evolve along a continuum of low to high responsiveness to cannibalistic foraging groups. Variation in predation pressure could have established a similar response framework.

The absence of parallelism of life history traits along the benthiclimnetic ecotypic continuum, or in relation to productivity, could reflect the absence of selection in the oceanic environment necessary to set up a binary flexible stem for life history along these environmental axes. An alternative possibility is that life history traits experience neither the functional constraints involved in the evolution of complex morphological phenotypes, nor are they constrained by the responses of ancestral, constitutive neural networks. Instead, life history phenotypes may be relatively free to respond to novel conditions with alternative combinations of genetic and plastic solutions to similar environmental challenges. Perhaps, life history phenotypes are best viewed as a matrix of traits, linked by resource constraints that can have far more variable combinations of genetic and plastic underpinnings than do morphology or behavior, making possible multiple alternative solutions to the same environmental challenge (Thorpe et al., 1998; Einum and Fleming, 2002). Life history traits, and the differing combinations of these traits observed among populations in this radiation may be adaptive, although population differences in fitness may exist. Given the tight association between life history and fitness, a reasonable explanation for the low parallelism in life history traits along environmental axes involves both variation in the composition of founder populations with respect both to genetic and plastic characteristics, and lesser phylogenetic constraint than may underlie patterns of variation in either morphology or behavior.

This insight is particularly interesting as behavioral phenotypes are largely viewed as first responders to novel environments, permitting populations to persist because they are more plastic than other aspects of phenotype ('Baldwin Effect' sensu Simpson, 1953) until natural selection can effect improved adaptation to the new environment. However, our research in Lynne Lake, Alaska makes clear that when environmental change has a major impact on plastic life history attributes such as maturation onset, size and longevity, shifts in life history can have marked effects on other aspects of phenotype, even including the re-emergence of ancestral behaviors including benthic foraging, cannibalism and diversionary display behavior (Chock, 2008). The shift in foraging is expected to have imposed a plastic change in morphology (Wund et al., 2008, 2012), a hypothesis we can test with collections during the transition, and ultimately is expected to lead to evolutionary modification of several aspects of phenotype- also testable given our long-term research on this population. The important message here is, however, that life history may often provide the first response to environmental shifts, particularly if mediated through effects on maturation onset, size and longevity.

One thing that is clear from this comparative approach is that the boundaries between the trait categories are blurred. This is particularly 
strongly emphasized by consideration of morphological plasticity in soft organs, in stickleback particularly including the brain and kidneys, both of which are at the interface between morphology and behavior, and are influenced by environment, and in the case of the brain, contexts for learning. Activational and developmental shifts in physiology also link morphology, life history and behavior, as do underlying patterns of gene expression (for example, Aubin-Horth and Renn, 2009; Renn and Schumer, 2013); (Piersma et al., 1996; Piersma and Drent, 2003; Piersma and Van Gils, 2011). Our increasing ability to examine the physiological, genetic and epigenetic changes underlying plasticity should make it possible to make rapid strides toward understanding the important, and often controversial role of plasticity in evolution (for example West-Eberhard, 2003; Laland et al., 2014; Wray et al., 2014).

\section{DATA ARCHIVING}

The data sets upon which Figures 2 and 4 are based are available from the Dryad Digital Repository: http://dx.doi.org/10.5061/dryad.884hv.

\section{CONFLICT OF INTEREST}

The authors declare no conflict of interest.

\section{ACKNOWLEDGEMENTS}

The authors thank Alison Bell, Justin Golub, and Katherine Shaw for comments on an early draft of the manuscript, and Pat Bateson and Juha Merilä for comments that very substantially improved the manuscript in revision. That said, any remaining errors are ours. The research from the laboratory of $S$ Foster and J Baker described here has been supported by Clark University and grants from the USA National Science Foundation and the National Institutes of Health, for which we are grateful. The data reported in Figure 2 complied with local laws and was carried out under The College of New Jersey Institutional Care and Use Committee protocol 1307-001MW1, and those in Figure 5 complied with local laws and were carried out under Clark University Institutional Care and Use Committee protocol 011R.

Abney MA, Rakocinski CF (2004). Life-history variation in Caribbean gambusia, Gambusia puncticulata puncticulata (Poeciliidae) from the Cayman Islands, British West Indies. Environ Biol Fish 70: 67-79.

Aguirre WE (2009). Microgeographic diversification of threespine stickleback: body shape-habitat correlations in a small, ecologically diverse Alaskan drainage. Biol J Linn Soc 98: 139-151.

Aguirre WE, Doherty PK, Bell MA (2004). Genetics of lateral plate and gill raker phenotypes in a rapidly evolving population of threespine stickleback. Behaviour 141.

Albert AYK, Sawaya S, Vines TH, Knecht AK, Miller CT, Summers BR et al. (2008). The genetics of adaptive shape shift in stickleback: pleiotropy and effect size. Evolution 62 76-85.

Ali M, Wootton R (1999). Coping with resource variation: effect of constant and variable intervals between feeding on reproductive performance at first spawning of female threespined sticklebacks. J Fish Biol 55: 211-220.

Angilletta MJ, Steury TD, Sears MW (2004). Temperature, growth rate, and body size in ectotherms: fitting pieces of a life-history puzzle. Integr Compar Biol 44: 498-509.

Aubin-Horth N, Renn SCP (2009). Genomic reaction norms: using integrative biology to understand molecular mechanisms of phenotypic plasticity. Mol Ecol 18: 3763-3780.

Auer SK (2010). Phenotypic plasticity in adult life-history strategies compensates for a poor start in life in Trinidadian guppies (Poecilia reticulata). Am Naturalist 176 818-829.

Baker JA, Cresko WC, Heins DC, Foster SA (2005). Life-history differentiation of benthic and limnetic ecotypes in a polytypic population of threespine stickleback (Gasterosteus aculeatus). Evol Ecol Res 7: 121-131.

Baker JA, Foster SA, Heins DC, Bell MA, King RW (1998). Variation in female life history traits among Alaskan populations of the threespine stickleback, Gasterosteus aculeatus (Pisces: Gasterosteidae). Biol J Linn Soc 63: 141-159.

Baker JA, Heins DC, Foster SA, King RW (2008). An overview of life-history variation in female threespine stickleback: patterns, scales and trait integration. Behaviour 145 579-602.

Baker JA, Wund MA, Heins DC, King RW, Reyes ML, Foster SA (2015). Life-history plasticity in female threespine stickleback. Heredity. (in press).
Baldwin JM (1902). Development and Evolution. Macmillan: New York, USA

Barlow GW (1977). Modal action patterns. In: Sebeok TA (eds). How Animals Communicate. Indiana University Press: Bloomington, IL, USA, pp 98-134.

Barot S, Heino M, O'Brien L, Dieckmann U (2004). Long-term trend in the maturation reaction norm of two cod stocks. Ecol App/ 14: 1257-1271.

Barrett RD, Rogers SM, Schluter D (2009). Environment specific pleiotropy facilitates divergence at the Ectodysplasin locus in threespine stickleback. Evolution 63 : 2831-2837.

Barrett RDH (2010). Adaptive evolution of lateral plates in three-spined stickleback Gasterosteus aculeatus: a case study in functional analysis of natural variation. J Fish Biol 77: 311-328.

Barrett RDH, Rogers SM, Schluter D (2008). Natural selection on a major armor gene in threespine stickleback. Science 322: 255-257.

Bateson P (1988). The active role of behaviour in evolution. In: Ho MW, Fox SW (eds). Evolutionary Processes and Metaphors. John Wiley and Sons: London, pp 191-207.

Bell AM, Sih A (2007). Exposure to predation generates personality in threespined sticklebacks (Gasterosteus aculeatus). Ecol Lett 10: 828-834.

Bell AM, Stamps JA (2004). Development of behavioural differences between individuals and populations of sticklebacks Gasterosteus aculeatus. Anim Behav 68: 1339-1348.

Bell MA, Foster SA (1994). Introduction to the evolutionary biology of the threespine stickleback. In: Bell MA, Foster SA (eds). The Evolutionary Biology of the Threespine Stickleback. Oxford University Press: Oxford, UK, pp 1-27.

Bell MA, Ortí G (1994). Pelvic reduction in threespine stickleback from Cook Inlet lakes: geographical distribution and intrapopulation variation. Copeia 1994: 314-325.

Bell MA, Orti G, Walker JA, Koenings JP (1993). Evolution of pelvic reduction in threespine stickleback fish-a test of competing hypotheses. Evolution 47: 906-914.

Bernardo J (1996). The particular maternal effect of propagule size, especially egg size: patterns, models, quality of evidence and interpretations. Am Zoologist 36: 216-236.

Berner D, Moser D, Roesti M, Buescher H, Salzburger W (2014). Genetic architecture of skeletal evolution in European lake and stream stickleback. Evolution 68: 1792-1805.

Bertschy KA, Fox MG (1999). The influence of age-specific survivorship on pumpkinseed sunfish life histories. Ecology 80: 2299-2313.

Borg B (2007). Reproductive physiology of sticklebacks. In: Ostlund-Nilsson S, Mayer I, Huntingford FA (eds). Biology of the Three-spined Stickleback. CRC Press: Boca Raton, FL, USA, pp 225-248.

Bradshaw AD (1965). Evolutionary significance of phenotypic plasticity in plants. $A d v$ Genet 13: 115-155.

Brown G, Shine R (2007). Repeatability and heritability of reproductive traits in freeranging snakes. J Evol Biol 20: 588-596.

Caswell H (1989). Life-history strategies. In: Cherret JM (eds). Ecological Concepts: The Contribution of Ecology to an Understanding of the Natural World. Blackwell Scientific: Boston, MA, USA, pp 285-307.

Chan Y, Marks M, Jones F, Villarreal Jr G, Shapiro M, Brady S et al. (2010). Adaptive evolution of pelvic reduction in sticklebacks by recurrent deletion of a Pitx 1 enhancer. Science 327: 302-305.

Chapman L, Albert J, Galis F (2008). Developmental plasticity, genetic differentiation, and hypoxia-induced trade-offs in an African cichlid fish. Open Evol J 2: 75-88.

Charlesworth B (1994). Evolution in Age-structured Populations Vol 2, Cambridge University Press: Cambridge, UK.

Charnov EL (1990). On evolution of age of maturity and the adult lifespan. J Evol Biol 3: 139-144.

Chock RY (2008). Re-emergence of ancestral plasticity and the loss of a rare limnetic phenotype in an Alaskan population of threespine stickleback. M.S. thesis, Clark University, Worcester, MA, USA.

Clague J, Harper JR, Hebda RJ, Howes D (1982). Late Quaternary sea levels and crustal movements, coastal British Columbia. Can J Earth Sci 19: 597-618.

Colosimo PF, Peichel CL, Nereng KS, Blackman BK, Shapiro MD, Schluter D et al. (2004). The genetic architecture of parallel armor plate reduction in threespine sticklebacks. PLoS Biol 2: 635-641.

Coyle SM, Huntingford FA, Peichel CL (2007). Parallel evolution of Pitx1 underlies pelvic reduction in Scottish threespine stickleback (Gasterosteus aculeatus). J Heredity 98: 581-586.

Cresko WA (2000). The Ecology And Geography Of Speciation: A Case Study Using An Adaptive Radiation Of Threespine Stickleback In Alaska. Clark University: Worcester, MA, USA.

Cresko WA, Amores A, Wilson C, Murphy J, Currey M, Phillips P et al. (2004). Parallel genetic basis for repeated evolution of armor loss in Alaskan threespine stickleback populations. Proc Natl Acad Sci USA 101: 6050-6055.

Crispo E, Chapman LJ (2008). Population genetic structure across dissolved oxygen regimes in an African cichlid fish. Mol Ecol 17: 2134-2148.

Crispo E, Chapman LJ (2010). Geographic variation in phenotypic plasticity in response to dissolved oxygen in an African cichlid fish. J Evol Biol.

Dall SR, Houston AI, McNamara JM (2004). The behavioural ecology of personality: consistent individual differences from an adaptive perspective. Ecol Lett 7: 734-739.

Day T, Pritchard J, Schluter D (1994). A comparison of 2 sticklebacks. Evolution 48: $1723-1734$

Day T, Rowe $L$ (2002). Developmental thresholds and the evolution of reaction norms for age and size at life-history transitions. Am Naturalist 159: 338-350.

de Fraipont M, FitzGerald GJ, Guderley H (1993). Age-related differences in reproductive tactics in the three-spined stickleback Gasterosteus aculeatus. Anim Behav 46: 961-968.

DeFaveri J, Merilä J (2013). Evidence for adaptive phenotypic differentiation in Baltic Sea sticklebacks. J Evol Biol 26: 1700-1715. 
DeWitt TJ, Sih A, Wilson DS (1998). Costs and limits of phenotypic plasticity. Trends Ecol Evol 13: 77-81.

Dingemanse NJ, Wright J, Kazem AJN, Thomas DK, Hickling R, Dawnay N (2007). Behavioural syndromes differ predictably between 12 populations of three-spined stickleback. J Anim Ecol 76: 1128-1138.

Dukas R (2013). Effects of learning on evolution: robustness, innovation and speciation. Anim Behav 85: 1023-1030.

Ebert TA, Hernández JC, Clemente S (2014). Annual reversible plasticity of feeding structures: cyclical changes of jaw allometry in a sea urchin. Proc $R$ Soc B Biol Sci 281 : 20132284

Einum S, Fleming IA (2002). Does within-population variation in fish egg size reflect maternal influences on optimal values? Am Naturalist 160: 756-765.

Foster SA (1988). Diversionary displays of paternal stickleback: defenses against cannibalistic groups. Behav Ecol Sociobiol 22: 335-340.

Foster SA (1994). Inference of evolutionary pattern: diversionary displays of threespine sticklebacks. Behav Ecol 5: 114-121.

Foster SA (1995). Understanding the evolution of behaviour in threespine stickleback: the value of geographic variation. Behaviour 132: 1107-1129.

Foster SA (2013a). Evolution of behavioural phenotypes: influences of ancestry and expression. Anim Behav 85: 1061-1075.

Foster SA (2013b). Evolutionary insights from behavioural geography: plasticity, evolution and responses to rapid environmental change. Evol Ecol Res 15: 705-731.

Foster SA, Baker JA (1995). Evolutionary interplay between ecology, morphology and reproductive behavior in threespine stickleback (Gasterosteus aculeatus L.). Environ Biol Fish 44: 213-223.

Foster SA, Baker JA (2004). Evolution in parallel: new insights from a classic system. Trends Ecol Evol 19: 456-459.

Foster SA, Scott RJ, Cresko WA (1998). Nested biological variation and speciation. Phil Trans $R$ Soc B 353: 207-218.

Foster SA, Shaw KA, Robert KL, Baker JA (2008). Benthic, limnetic and oceanic threespine stickleback: profiles of reproductive behaviour. Behaviour 145: 485-508.

Giesing ER, Suski CD, Warner RE, Bell AM (2011). Female sticklebacks transfer information via eggs: effects of maternal experience with predators on offspring. Proc $R$ Soc B Biol Sci 278: 1753-1759.

Goldschmidt T, Foster SA, Sevenster P (1992). Inter-nest distance and sneaking in the three-spined stickleback. Anim Behav 44: 793-795.

Golub JL (2013). Embryonic Learning in Threespine Stickleback (Gasterosteus aculeatus). PhD thesis, Clark University: Worcester, MA.

Gonda A, Herczeg G, Merilä J (2011a). Population variation in brain size of nine-spined sticklebacks (Pungitius pungitius)-local adaptation or environmentally induced variation? BMC Evol Biol 11: 75.

Gonda A, Herczeg G, Merilä J (2013). Evolutionary ecology of intraspecific brain size variation: a review. Ecol Evol 3: 2751-2764.

Gonda A, Välimäki K, Herczeg G, Merilä J (2011b). Brain development and predation: plastic responses depend on evolutionary history. Biol Lett 8: 249-252.

Goodson JL (2005). The vertebrate social behavior network: evolutionary themes and variations. Horm Behav 48: 11-22.

Gotthard K, Nylin S (1995). Adaptive plasticity and plasticity as an adaptation: a selective review of plasticity in animal morphology and life history. Oikos 3-17.

Gunderson DR, Dygert PH (1988). Reproductive effort as a predictor of natural mortality rate. J Cons int Explor Mer 44: 200-209.

Hallgrímsson B, Hall BK (2011). Introduction. In: Hallgrímsson B, Hall BK (eds) Epigenetics: Linking Genotype and Phenotype in Development and Evolution. University of California Press: Berkeley, pp 1-8.

Hart PJB, Gill AB (1994). Evolution of foraging behaviour in the threespine stickleback In: Bell MA, Foster SA (eds). The Evolutionary Biology of the Threespine Stickleback. Oxford University Press: Oxford, UK, pp 207-239.

Heins DC, Baker JA (1993). Reproductive biology of the brighteye darter, Etheostoma Iynceum (Teleostei: Percidae), from the Homochitto River, Mississippi. Ichthyol Explor Fresw 4: 11-20.

Heins DC, Barry KA, Petrauskas LA (2014). Consistency of host responses to parasitic infection in the three-spined stickleback fish infected by the diphyllobothriidean cestode Schistocephalus solidus. Biol J Linn Soc 113: 958-968.

Hendry AP, Peichel CL, Matthews B, Boughman JW, Nosil P (2013). Stickleback research: the now and the next. Evol Ecol Res 15: 111-141.

Hohenlohe P, Bassham S, Etter P, Stiffler N, Johnson E, Cresko W (2010). Population genomics of parallel adaptation in threespine stickleback using sequenced RAD tags. PLoS Genet 6: e1000862.

Hohenlohe PA, Bassham S, Currey M, Cresko WA (2012). Extensive linkage disequilibrium and parallel adaptive divergence across threespine stickleback genomes. Phil Trans $R$ Soc B 367: 395-408.

Huntingford FA (1976). Relationship between anti-predator behavior and aggression among conspecifics in 3-spined stickleback Gasterosteus aculeatus. Anim Behav 24: 245-260.

Imre I, McLaughlin RL, Noakes DLG (2002). Phenotypic plasticity in brook charr: changes in caudal fin induced by water flow. J Fish Biol 61: 1171-1181.

Johnson LS, Taylor EB (2004). The distribution of divergent mitochondrial DNA lineages of threespine stickleback (Gasterosteus aculeatus) in the northeastern Pacific Basin: postglacial dispersal and lake accessibility. J Biogeogr 31: 1073-1083.

Jones FC, Chan YF, Schmutz J, Grimwood J, Brady SD, Southwick AM et al. (2012a). A genome-wide SNP genotyping array reveals patterns of global and repeated speciespair divergence in sticklebacks. Curr Biol 22: 83-90.
Jones FC, Grabherr MG, Chan YF, Russell P, Mauceli E, Johnson J et al. (2012b) The genomic basis of adaptive evolution in threespine sticklebacks. Nature 484 55-61.

Kennedy J, Witthames PR, Nash RD (2007). The concept of fecundity regulation in plaice (Pleuronectes platessa) tested on three Irish Sea spawning populations. Can J Fish Aquatic Sci 64: 587-601.

Kindsvater HK, Alonzo SH (2014). Females allocate differentially to offspring size and number in response to male effects on female and offspring fitness. Proc $R$ Soc B Biol Sci 281: 20131981.

Kingsolver JG, Hoekstra HE, Hoekstra JM, Berrigan D, Vignieri SN, Hill C et al. (2001). The strength of phenotypic selection in natural populations. Am Naturalist 157: 245-261.

Kolm N (2001). Females produce larger eggs for large males in a paterna mouthbrooding fish. Proc $R$ Soc B Biol Sci 268: 2229-2234.

Krebs JR, Davies NB (1993). Behavioural Ecology: An Evolutionary Approach, 3rd edn. Blackwell: Oxford, UK.

Laland K, Uller T, Feldman M, Sterelny K, Müller GB, Moczek A et al. (2014). Does evolutionary theory need a rethink? Nature 514: 161.

Laskowski KL, Bell AM (2013). Competition avoidance drives individual differences in response to a changing food resource in sticklebacks. Ecol Lett 16: 746-753.

Lavin PA, McPhail JD (1986). Adaptive divergence of trophic phenotype among freshwater populations of threespine stickleback (Gasterosteus aculeatus). Can J Fish Aquat Sci 43: 2455-2463.

Le Rouzic A, ØStbye K, Klepaker TO, Hansen TF, Bernatchez L, Schluter D et al. (2011). Strong and consistent natural selection associated with armour reduction in sticklebacks. Mol Ecol 20: 2483-2493.

Leinonen T, Herczeg G, Cano JM, Merilä J (2011). Predation-imposed selection on threespine stickleback (Gasterosteus aculeatus) morphology: a test of the refuge use hypothesis. Evolution 65: 2916-2926.

Leips J, Helen Rodd F, Travis J (2013). The adaptive significance of population differentiation in offspring size of the least killifish, Heterandria formosa. Ecol Evol 3 948-960.

Lescak EA, von Hippel FA (2011). Selective predation of threespine stickleback by rainbow trout. Ecol Freshw Fish 20: 308-314.

Lescak EA, von Hippel FA, Lohman BK, Sherbick ML (2012). Predation of threespine stickleback by dragonfly naiads. Ecol Freshw Fish 581-587.

Loehr J, Leinonen T, Herczeg G, O'Hara RB, Merilä J (2012). Heritability of asymmetry and lateral plate number in the threespine stickleback. PloS One 7: e39843.

Love OP, McGowan PO, Sheriff MJ (2013). Maternal adversity and ecological stressors in natural populations: the role of stress axis programming in individuals, with implications for populations and communities. Funct Ecol 27: 81-92.

Marchinko KB (2009). Predation's role in repeated phenotypic and genetic divergence of armor in threespine stickleback. Evolution 63: 127-138.

Mathews WH, Fyles J, Nasmith H (1970). Postglacial crustal movements in southwestern British Columbia and adjacent Washington State. Can J Earth Sci 7: 690-702.

Mazzarella AVB (2010). Ovulation, oviposition and Stress in the Female Threespine Stickleback, Gasterosteus aculeatus. M.S. thesis, Clark University: Worcester, MA USA.

McCairns RJS, Bernatchez L Development and Evolution(2010). Adaptive divergence between freshwater and marine sticklebacks: insights into the role of phenotypic plasticity from an integrated analysis of candidate gene expression. Evolution 64 1029-1047.

McCairns RJS, Bernatchez L (2012). Plasticity and heritability of morphological variation within and between parapatric stickleback demes. J Evol Biol 25 1097-1112.

McCormick MI (1998). Behaviorally induced maternal stress in a fish influences progeny quality by a hormonal mechanism. Ecology 79: 1873-1883.

McGhee KE, Pintor LM, Suhr EL, Bell AM (2012). Maternal exposure to predation risk decreases offspring antipredator behaviour and survival in threespined stickleback. Funct Ecol 932-940.

McGuigan K, Nishimura N, Currey M, Hurwit D, Cresko WA (2010). Quantitative genetic variation in static allometry in the threespine stickleback. Integr Comp Biol 50: $1067-1080$

McPhail J (1977). Inherited interpopulation differences in size at first reproduction in threespine stickleback, Gasterosteus aculeatus L. Heredity 38: 53-60.

McPhail JD (1994). Speciation and the evolution of reproductive isolation in the sticklebacks (Gasterosteus) of south-western British Columbia. In: Bell MA, Foster SA (eds) The Evolutionary Biology of the Threespine Stickleback. Oxford University Press: Oxford, UK, pp 399-437.

Mehlis M, Bakker TC (2013). Male reproductive traits of full-sibs of different age classes in three-spined sticklebacks (Gasterosteus aculeatus). SpringerPlus 2: 175.

Milinski M (1988). Games fish play: making decisions as a social forager. Trends Ecol Evol 3: 325-330.

Moczek AP, Sultan SE, Foster SA, Ledon-Rettig CC, Dworkin I, Nijhout HF et al. (2011). The role of developmental plasticity in evolutionary innovation. Proc $R$ Soc B Biol $\mathrm{Sci}$ 278: 2705-2713.

Mommer BC, Bell AM (2013). A test of maternal programming of offspring stress response to predation risk in threespine sticklebacks. Physiol Behav 122: 222-227.

Mommer BC, Bell AM (2014). Maternal experience with predation risk influences genomewide embryonic gene expression in threespined sticklebacks (Gasterosteus aculeatus). PloS One 9: e98564.

Moran NA (1992). The evolutionary maintenance of alternative phenotypes. Am Naturalist 139: 971-989.

Morgan CL (1896). On modification and variation. Science 4: 733-740. 
Morita K, Fukuwaka Ma (2006). Does size matter most? The effect of growth history on probabilistic reaction norm for salmon maturation. Evolution 60: 1516-1521.

Mousseau TA, Fox CW (1998). The adaptive significance of maternal effects. Trends Ecol Evolution 13: 403-407.

Mousseau TA, Roff DA (1987). Natural selection and the heritability of fitness components. Heredity 59: 181-197.

Münzing J (1963). The evolution of variation and distributional patterns in European populations of the three-spined stickleback, Gasterosteus aculeatus. Evolution 17: 320-332.

Nylin S, Gotthard K (1998). Plasticity in life-history traits. Annu Rev Entomol 43: 63-83.

O'Connell LA, Hofmann HA (2011). The vertebrate mesolimbic reward system and social behavior network: a comparative synthesis. J Comp Neurol 519: 3599-3639.

O'Neill S (2012). Retention of an unexpressed ancestral behavior in threespine stickleback (Gasterosteus aculeatus). MA thesis, Clark University, Worcester, MA, USA.

Oravec T, Reimchen T (2012). Divergent reproductive life histories in Haida Gwaii stickleback (Gasterosteus spp.). Can J Zool 91: 17-24.

Orti G, Bell MA, Reimchen TE, Meyer A (1994). Global survey of mitochondrial DNA sequences in the threespine stickleback: evidence for recent migrations. Evolution 48: 608-622.

Östlund-Nilsson S (2007). Reproductive behaviour in the three-spined stickleback. In: Östlund-Nilsson S, Mayer I, Huntingford FA(eds). Biology of the Three-spined Stickleback. CRC Press: Boca Raton, FL, USA, pp 157-178.

Östlund-Nilsson S, Mayer I, Huntingford FA (eds) (2007). Biology of the Three-spined Stickleback. Taylor \& Francis: Boca Raton, FL, USA.

Paaby AB, Rockman MV (2014). Cryptic genetic variation: evolution's hidden substrate. Nat Rev Genet 15: 247-258.

Padilla DK, Adolph SC (1996). Plastic inducible morphologies are not always adaptive: the importance of time delays in a stochastic environment. Evol Ecol 10: 105-117.

Pakkasmaa S, Piironen J (2000). Water velocity shapes juvenile salmonids. Evol Ecol 14

Park PJ, Chase I, Bell MA (2012). Phenotypic plasticity of the threespine stickleback Gasterosteus aculeatus telencephalon in response to experience in captivity. Curr Zool 58: 189-210.

Peichel CL, Nereng KS, Ohgi KA, Cole BLE, Colosimo PF, Buerkle CA et al. (2001). The genetic architecture of divergence between threespine stickleback species. Nature 414 901-905.

Pfennig DW, Wund MA, Snell-Rood EC, Cruickshank T, Schlichting CD, Moczek AP (2010). Phenotypic plasticity's impacts on diversification and speciation. Trends Ecol Evol 25: 459-467.

Piersma T, Bruinzeel L, Drent R, Kersten M, Van der Meer J, Wiersma P (1996). Variability in basal metabolic rate of a long-distance migrant shorebird (red knot, Calidris canutus) reflects shifts in organ sizes. Physiol Zool 191-217.

Piersma T, Drent J (2003). Phenotypic flexibility and the evolution of organismal design. Trends Ecol Evol 18: 228-233.

Piersma T, Van Gils JA (2011). The Flexible Phenotype: a Body-centred Integration of Ecology, Physiology, and Behaviour. Oxford University Press: Oxford, UK.

Poizat G, Rosecchi E, Crivelli AJ (1999). Empirical evidence of a trade-off between reproductive effort and expectation of future reproduction in female three-spined sticklebacks. Proc R Soc B Biol Sci 266: 1543-1548.

Reger RD, Pinney DS (1996). Late Wisconsin glaciation of the Cook Inlet Region with emphasis on the Kenai lowland and implications for early peopling. In: David NY, Davids WE (eds). Adventures Through Time: Readings in the Anthropology of Cook Inlet, Alaska. Cook Inlet Historical Society: Anchorage, AK, USA, pp 15-35.

Reimchen TE (1992). Injuries on stickleback from attacks by a toothed predator (Oncorhynchus) and implications for the evolution of lateral plates. Evolution 46: 1224-1230.

Reimchen TE (1994). Predators and morphological evolution in threespine stickleback. In: Bell MA, Foster SA (eds). The Evolutionary Biology of the Threespine Stickleback. Oxford University Press: Oxford, UK, pp 240-276.

Renn SC, Schumer ME (2013). Genetic accommodation and behavioural evolution: insights from genomic studies. Anim Behav 85: 1012-1022.

Reznick D, Nunney L, Tessier A (2000). Big houses, big cars, superfleas and the costs of reproduction. Trends Ecol Evol 15: 421-425.

Reznick DA, Bryga H, Endler JA (1990). Experimentally induced life-history evolution in a natural population. Nature 346: 357-359.

Roche DP, McGhee KE, Bell AM (2012). Maternal predator-exposure has lifelong consequences for offspring learning in threespined sticklebacks. Biol Lett 8: 932-935.

Rodd FH, Reznick DN, Sokolowski MB (1997). Phenotypic plasticity in the life history traits of guppies: responses to social environment. Ecology 78: 419-433.

Roe A, Simpson GG (eds) (1958). Behavior and Evolution. Yale University Press: New Haven, CT, USA, p 557

Roff D (2000). Trade-offs between growth and reproduction: an analysis of the quantitative genetic evidence. J Evol Biol 13: 434-445

Rowland WJ (1994). Proximate determinants of stickleback behaviour: an evolutionary perspective. In: Bell MA, Foster SA (eds). The Evolutionary Biology of the Threespine Stickleback. Oxford University Press: Oxford, UK, pp 297-344.

Saito T, Nakano S (1999). Reproductive-timing-dependent alternation of offspring life histories in female threespine sticklebacks. Can J Zool 77: 1314-1321.

Sargent RC (1982). Territory quality, male quality, courtship intrusions, and female nest-choice in the threespine stickleback Gasterosteus aculeatus. Anim Behav 30: 364-374.

Scheiner SM (1993). Genetics and evolution of phenotypic plasticity. Annu Rev Ecol Syst 24: $35-68$
Schlichting CD, Pigliucci M (1998). Phenotypic Evolution: a Reaction Norm Perspective. Sinauer: Sunderland, MA, USA.

Schluter D (2000). The Ecology of Adaptive Radiation. Oxford University Press: Oxford, UK. Schneider L (1969). Experimentelle untersuchungen über den einfluß von tageslänge und temperatur auf die gonadenreifung beim dreistachligen stichling (Gasterosteus aculeatus). Oecologia 3: 249-265.

Segers FH, Taborsky B (2011). Egg size and food abundance interactively affect juvenile growth and behaviour. Funct Ecol 25: 166-176.

Shapiro MD, Marks ME, Peichel CL, Blackman BK, Nereng KS, Bjarni J et al. (2004). Genetic and developmental basis of evolutionary pelvic reduction in threespine sticklebacks. Nature 428: 717-723.

Shaw KA (2014). Ancestral variation and the evolution of sneaking behavior in the adaptive radiation of threespine stickleback (Gasterosteus aculeatus L.). Ph.D. thesis, University of Connecticut: Storrs, CT, USA.

Shaw KA, Scotti ML, Foster SA (2007). Ancestral plasticity and the evolutionary diversification of courtship behaviour in threespine sticklebacks. Anim Behav 73 : $415-422$.

Sih A (2004). A behavioral ecological view of phenotypic plasticity. In: DeWitt TJ, Scheiner SM (eds). Phenotypic Plasticity: Functional and Conceptual Approaches. Oxford Univerisity Press: New York, NY, USA, pp 112-125.

Sih A, Bell AM, Johnson JC (2004a). Reply to Neff and Sherman. Behavioral syndromes versus darwinian algorithms. Trends Ecol Evol 19: 622-623.

Sih A, Bell AM, Johnson JC, Ziemba RE (2004b). Behavioral syndromes: an integrative overview. Q Rev Biol 79: 241-277.

Simpson GG (1953). The Baldwin effect. Evolution 7: 110-117.

Snell-Rood EC (2013). An overview of the evolutionary causes and consequences of behavioural plasticity. Anim Behav.

Snell-Rood EC, Van Dyken JD, Cruickshank T, Wade MJ, Moczek AP (2010). Toward a population genetic framework of developmental evolution: the costs, limits, and consequences of phenotypic plasticity. Bioessays 32: 71-81.

Snyder RJ (1991). Quantitative genetic analysis of life histories in two freshwater populations of the threespine stickleback. Copeia 526-529.

Snyder RJ, Dingle H (1989). Adaptive, genetically based differences in life history between estuary and freshwater threespine sticklebacks (Gasterosteus aculeatus L.). Can J Zool 67: $2448-2454$

Stearns SC (1992). The Evolution of Life Histories. Vol 249, Oxford University Press: Oxford, UK.

Stephens DW, Brown J, Ydenberg RC (eds) (2007). Foraging: Behavior and Ecology. University of Chicago Press: Chicago, IL, USA

Thompson D (1999). Different spatial scales of natural selection and gene flow: the evolution of behavioral geographic variation and phenotypic plasticity. In: Foster SA, Endler JA (eds). Geographic Variation in Behavior: Perspectives on Evolutionary Mechanisms. Oxford University Press: New York, NY, USA, pp 33-51.

Thorpe JE, Mangel M, Metcalfe NB, Huntingford FA (1998). Modelling the proximate basis of salmonid life-history variation, with application to Atlantic salmon, Salmo salar L. Evol Ecol 12: 581-599.

Tinbergen N (1951). The Study of Instinct. Oxford University Press: Oxford, UK.

Tollrian R, Harvell CD (1999). The Ecology and Evolution of Inducible Defenses. Princeton University Press: Princeton, USA.

Tramontin AD, Brenowitz EA (2000). Seasonal plasticity in the adult brain. Trends Neurosci 23: $251-258$.

Trexler JC (1997). Resource availability and plasticity in offspring provisioning: embryo nourishment in sailfin mollies. Ecology 78: 1370-1381.

Trippel EA, Harvey HH (1989). Missing opportunities to reproduce: an energy dependent or fecundity gaining strategy in white sucker (Catostomus commersoni)? Can J Zoo 67: 2180-2188

van den Assem J (1967). Territory in the three-spined stickleback Gasterosteus aculeatus L. an experimental study in intra-specific competition. Behav Suppl: III, V-VIII, pp $1-164$.

Walker JA (1997). Ecological morphology of lacustrine threespine stickleback Gasterosteus aculeatus L. (Gasterosteidae) body shape. Biol J Linn Soc 61: 3-50.

Walker JA, Bell MA (2000). Net evolutionary trajectories of body shape evolution within a microgeographic radiation of threespine stickleback (Gasterosteus aculeatus). J Zool Soc London 252: 293-302.

Wcislo WT (1989). Behavioral environments and evolutionary change. Annu Rev Ecol Syst 20: $137-169$.

Weismann A (1894). The effect of external influences upon development. H. Frowde.

West-Eberhard MJ (1989). Phenotypic plasticity and the origins of diversity. Annu Rev Ecol Syst 20: 249-278.

West-Eberhard MJ (2003). Developmental Plasticity and Evolution. Oxford University Press: New York, NY, USA.

Westneat DF, Fox CW (eds) (2010). Evolutionary Behavioural Ecology. Oxford Univeristy Press: Oxfor, UK.

Willacker J, von Hippel F, Wilton P, Walton K (2010). Classification of threespine stickleback along the benthic-limnetic axis. Biol J Linn Soc 101: 595-608.

Wilson DS, Clark AB, Coleman K, Dearstyne T (1994). Shyness and boldness in humans and other animals. Trends Ecol Evol 9: 442-446.

Wilz KJ (1972). Causal relationships between aggression and the sexual and nest behaviours in the three-spined stickleback (Gasterosteus aculeatus). Anim Behav 20: 335-340.

Withler RE, McPhail JD (1985). Genetic variability in freshwater and anadromous sticklebacks (Gasterosteus aculeatus) of southern British Columbia. Can J Zool 63: 528-533. 
Wootton R (1973). Fecundity of the three-spined stickleback, Gasterosteus aculeatus (L.) J Fish Biol 5: 683-688.

Wootton RJ (1976). The Biology of the Stickleback. Academic Press: : London, UK

Wootton RJ, Fletcher D (2009). Effect of spawning number and ration on reproductive performance of the batch-spawning three-spined stickleback Gasterosteus aculeatus. J Fish Biol 75: 618-629.

Wray GA, Hoekstra HE, Futuyma DJ, Lenski RE, Mackay TF, Schluter D et al. (2014). Does evolutionary theory need a rethink? No, all is well. Nature 514: 161-164.

Wund MA (2012). Assessing the impacts of phenotypic plasticity on evolution. Integr Comp Biol 52: 5-15
Wund MA, Baker JA, Clancy B, Golub J, Foster SA (2008). A test of the 'flexible stem' model of evolution: ancestral plasticity, genetic accommodation, and morphological divergence in the threespine stickleback radiation. Am Naturalist 172. 449-462.

Wund MA, Baker JA, Golub JL, Foster SA (2015). The evolution of antipredator behaviour following relexed and reversed selection in Alaskan threespine stickleback fish. Anim Behav, in press.

Wund MA, Valena S, Wood S, Baker JA (2012). Ancestral plasticity and allometry in threespine stickleback fish reveal phenotypes associated with derived, freshwater ecotypes. Biol J Linn Soc 105: 573-583. 